\title{
Integrated maps in quail (Coturnix japonica) confirm the high degree of synteny conservation with chicken (Gallus gallus) despite 35 million years of divergence
}

\author{
Boniface B Kayang1,5, Valérie Fillon¹, Miho Inoue-Murayama², Mitsuru Miwa², Sophie Leroux¹, \\ Katia Fève ${ }^{1}$, Jean-Louis Monvoisinn ${ }^{3}$, Frédérique Pitel ${ }^{1}$, Matthieu Vignoles ${ }^{1}$, Céline Mouilhayrat ${ }^{1}$, \\ Catherine Beaumont ${ }^{4}$, Shin'ichi Ito ${ }^{2}$, Francis Minvielle ${ }^{3}$ and Alain Vignal*1
}

Address: ${ }^{1}$ Laboratoire de Génétique Cellulaire, Centre INRA de Toulouse, BP 52627 Auzeville, 31326 Castanet Tolosan, France, ${ }^{2}$ Faculty of Applied Biological Sciences, Gifu University, Gifu 501-1193, Japan, ${ }^{3}$ UMR Génétique et Diversité Animales, INRA bât 211, 78352 Jouy-en-Josas Cedex, France, ${ }^{4}$ Station de Recherches Avicoles, INRA, 37380 Nouzilly, France and ${ }^{5}$ Department of Animal Science, University of Ghana, Legon, Accra, Ghana

Email: Boniface B Kayang - bbkayang@ug.edu.gh; Valérie Fillon - valerie.fillon@toulouse.inra.fr; Miho Inoue-Murayama - miho-i@cc.gifuu.ac.jp; Mitsuru Miwa - j4111028@guedu.cc.gifu-u.ac.jp; Sophie Leroux - sleroux@toulouse.inra.fr; Katia Fève - katia.feve@toulouse.inra.fr; Jean-Louis Monvoisin - jean-louis.monvoisin@dga.jouy.inra.fr; Frédérique Pitel - frederique.pitel@toulouse.inra.fr; Matthieu Vignoles - matthieu.vignoles@argene.com; Céline Mouilhayrat - mouilhayrat@hotmail.com;

Catherine Beaumont - beaumont@tours.inra.fr; Shin'ichi Ito - ito-s@cc.gifu-u.ac.jp; Francis Minvielle - ugenfpg@dga2.jouy.inra.fr; Alain Vignal* - alain.vignal@toulouse.inra.fr

* Corresponding author

Published: 02 May 2006

Received: 08 December 2005

BMC Genomics 2006, 7:101 doi:10.1186/147|-2164-7-101

Accepted: 02 May 2006

This article is available from: http://www.biomedcentral.com/l47/-2/64/7//0I

(c) 2006 Kayang et al; licensee BioMed Central Ltd.

This is an Open Access article distributed under the terms of the Creative Commons Attribution License (http://creativecommons.org/licenses/by/2.0), which permits unrestricted use, distribution, and reproduction in any medium, provided the original work is properly cited.

\begin{abstract}
Background: By comparing the quail genome with that of chicken, chromosome rearrangements that have occurred in these two galliform species over 35 million years of evolution can be detected. From a more practical point of view, the definition of conserved syntenies helps to predict the position of genes in quail, based on information taken from the chicken sequence, thus enhancing the utility of this species in biological studies through a better knowledge of its genome structure. A microsatellite and an Amplified Fragment Length Polymorphism (AFLP) genetic map were previously published for quail, as well as comparative cytogenetic data with chicken for macrochromosomes. Quail genomics will benefit from the extension and the integration of these maps.

Results: The integrated linkage map presented here is based on segregation analysis of both anonymous markers and functional gene loci in I,050 quail from three independent F2 populations. Ninety-two loci are resolved into 14 autosomal linkage groups and a $Z$ chromosome-specific linkage group, aligned with the quail AFLP map. The size of linkage groups ranges from $7.8 \mathrm{cM}$ to $274.8 \mathrm{cM}$. The total map distance covers $904.3 \mathrm{cM}$ with an average spacing of $9.7 \mathrm{cM}$ between loci. The coverage is not complete, as macrochromosome CJA08, the gonosome CJAW and 23 microchromosomes have no marker assigned yet. Significant sequence identities of quail markers with chicken enabled the alignment of the quail linkage groups on the chicken genome sequence assembly. This, together with interspecific Fluorescence In Situ Hybridization (FISH), revealed very high similarities in marker order between the two species for the eight macrochromosomes and the 14 microchromosomes studied.

Conclusion: Integrating the two microsatellite and the AFLP quail genetic maps greatly enhances the quality of the resulting information and will thus facilitate the identification of Quantitative Trait Loci (QTL). The alignment with the chicken chromosomes confirms the high conservation of gene order that was expected between the two species for macrochromosomes. By extending the comparative study to the microchromosomes, we suggest that a wealth of information can be mined in chicken, to be used for genome analyses in quail.
\end{abstract}




\section{Background}

The Japanese quail (Coturnix japonica) is valued for its uniquely flavored eggs and meat and is reared in many countries of the world, particularly on a large scale in China, Japan, Brazil, Hong-Kong, France and Spain [1]. It is also an important animal model used in a range of scientific disciplines including embryonic development [2], behavior [3], physiology [4], genetics [5] and biomedicine [6]. In common with its close relative species the chicken, Japanese quail belongs to the the family Phasianidae in the order Galliformes and the two species have diverged 35 million years ago $[7,8]$. They have a karyotype of $2 n=$ 78 chromosomes comprising a few morphologically distinct macrochromosomes (1-8 and the ZW sex chromosomes) and numerous cytologically indistinguishable microchromosomes. Moreover, chromosome homology between both species has been reported to be highly conserved, revealing only very few rearrangements [9]. This enables the nomenclature of the quail chromosomes (CJA for Coturnix japonica) to follow that of chicken by using corresponding numbers as suggested by the marker and gene data. However, unlike chicken where the majority of avian genomic studies have focused, much remains to be done on quail and other agriculturally and biologically important species. With the completion of the chicken genome map and sequence, a solid foundation has been laid on which comparative maps can be made for the lessstudied poultry species. From this viewpoint, quail genome mapping would greatly profit from the unique relation between quail and chicken.

To further enhance the genetic improvement of this species as a food animal and also boost its potential as a research model for poultry, we have initiated mapping efforts in the Japanese quail, for which molecular information has been scarce until now. Indeed, mapping in quail has progressed from just three classical linkage groups based on plumage color and blood protein markers [10-13] to the first ever DNA-based genetic map constructed solely with AFLP markers [14] and to the recent microsatellite-based map [15]. However, both DNAbased maps were not only developed with different types of markers, but also used distinct populations. Therefore, to establish links between them, we genotyped markers from the microsatellite map in the population previously used for the AFLP map. Also, by adding a third mapping population, new microsatellite markers that were previously uninformative could be added to the integrated map.

Finally, to establish stronger links to the chicken maps and assembled sequence, we used three strategies: (i) gene loci were mapped in one population by developing Single Nucleotide Polymorphism (SNP) markers, (ii) microsatellite markers were located on the chicken sequence assembly by BLASTN searches, and (iii) comparative cytogenetic studies were conducted by means of FISH experiments.

\section{Results}

Three mapping populations were used in the present study. Population 1 (Pop1) had previously been used to construct an AFLP map of quail and to map QTL for behavior traits [16]; population 2 (Pop2) to derive the first microsatellite map in quail and to map QTL $[15,17]$; and finally, population 3 (Pop3) to map plumage color and blood protein loci by microsatellite genotyping [18].

\section{Comprehensive microsatellite and gene maps}

All the microsatellite markers available and informative were genotyped in Pop2 and Pop3, thus adding 14 markers to the previously published map. As the information on quail genes available in the public databases was scarce, to detect SNP in quail we opted to choose primers from chicken Expressed Sequence Tags (EST) with the understanding that the two species are closely related and, therefore, have highly conserved genes. All functional gene markers developed from chicken EST were tested by PCR for their suitability to amplify quail DNA, and the quail amplicon was sequenced in both forward and reverse directions to confirm orthology. Detection of polymorphism and genotyping of Type I markers were done only on Pop 1 by Single Strand Conformation Polymorphism (SSCP) analysis. Therefore, to link together the microsatellite maps derived from Pop2 and Pop3 to the AFLP and gene-containing map derived from Pop1, a set of 63 microsatellite markers was chosen from the first microsatellite map [15] for genotyping Pop1. The choice of microsatellites was based on their position in the linkage group, so as to cover the entire map with a minimal set of markers to be used as anchor points.

In all, 112 markers comprising 90 microsatellites and 22 functional genes were analyzed by two-point linkage analysis including the genotype data from the three populations. The number of informative meioses in the comprehensive F2 mapping population of 1,050 quail varied from 42 to 1,618 with an average of 726 per locus and was therefore sufficient to assure high levels of support for ordering the linkage groups. Ninety-two of the markers, representing 74 microsatellites and 18 genes, were resolved into 14 autosomal linkage groups and a $\mathrm{Z}$ chromosome-specific linkage group (Figure 1 to 8 ) while the remaining 20 markers (16 microsatellites and four genes) showed no linkage to any other marker. The size of the linkage groups ranges from $7.8 \mathrm{cM}$ (CJA14) to 274.8 cM (CJA01) and the overall map coverage within linkage groups is $904.3 \mathrm{cM}$ with an average spacing of $9.7 \mathrm{cM}$ between loci. Thus, the integration of data from the three mapping populations and the inclusion of additional 


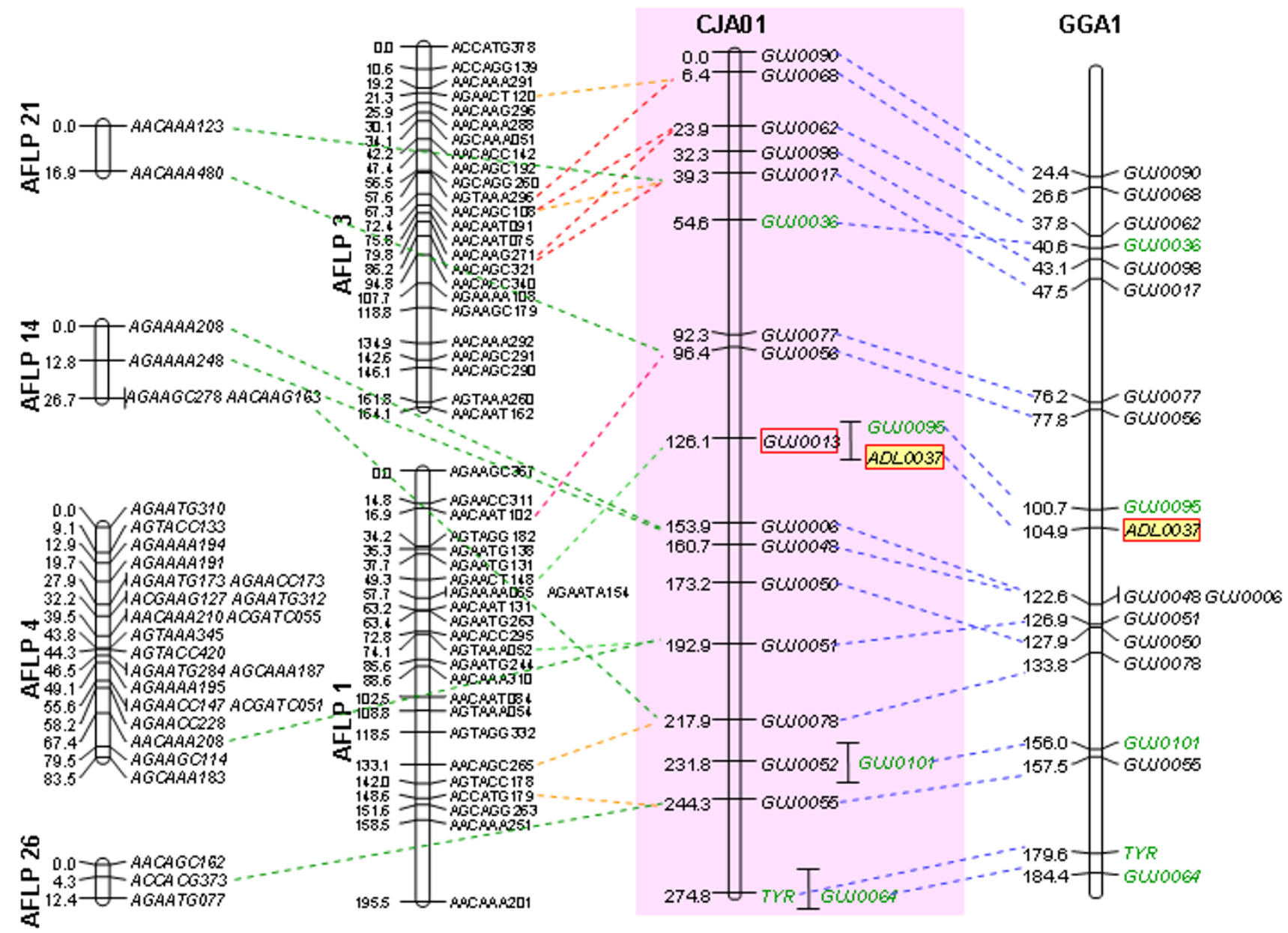

\section{Figure I}

Alignments of Japanese quail microsatellite and AFLP maps and links to the assembled chicken sequence. Left: AFLP linkage groups from [14]; center: integrated microsatellite and gene map (this study); right: chicken February 2004 sequence assembly [22]. AFLP and microsatellite genetic maps are in cM and the sequence assembly is in Mb. New quail linkage groups have blue titles and new microsatellite and gene markers are in green. Genes are in boldface italic. Microsatellite markers informative in both species are in red boxes. Chicken markers have a yellow background. Quail microsatellites or genes with similarity to chicken sequence of unknown location (chrun) have a blue background. Dotted lines linking the microsatellite and the AFLP maps indicate positive results of two-point linkage between the markers, with supporting LOD scores of 3 to 6 (green), 6 to 10 (orange) or more than 10 (red).

markers has enabled the extension of the microsatellite and gene-containing linkage groups from $576 \mathrm{cM}[15]$ to $904 \mathrm{cM}$. Most of the functional gene markers were assigned to CJA02 since they were developed for chromosome 2 as part of a study to confirm a putative QTL.

\section{Aligning the comprehensive map to the AFLP map}

After microsatellite genotyping in Pop1, two-point linkage analysis between these new markers and the AFLP was used to establish the links with the maps derived from Pop2 and Pop3. Overall, by using a LOD score threshold of $3.0,31$ out of the 41 AFLP linkage groups were linked to 13 out of the 15 microsatellite linkage groups (Figure 1 to 8$)$. The remaining 10 AFLP linkage groups were amongst the smallest. This suggests that neither map has a complete coverage of the genome. CJA01 and CJA03 had links to as many as six and seven AFLP groups, respectively (Figure 1 to 8 ). Generally, large AFLP linkage groups were associated with linkage groups assigned to macrochromosomes (e.g. CJA01 - CJA07) while small AFLP groups were linked to integrated linkage groups assigned to microchromosomes (e.g. CJA09 - CJA27). Both the Z and W AFLP groups, however, were linked to the Z-linked group CJAZ. In some instances, one AFLP linkage group is linked to 


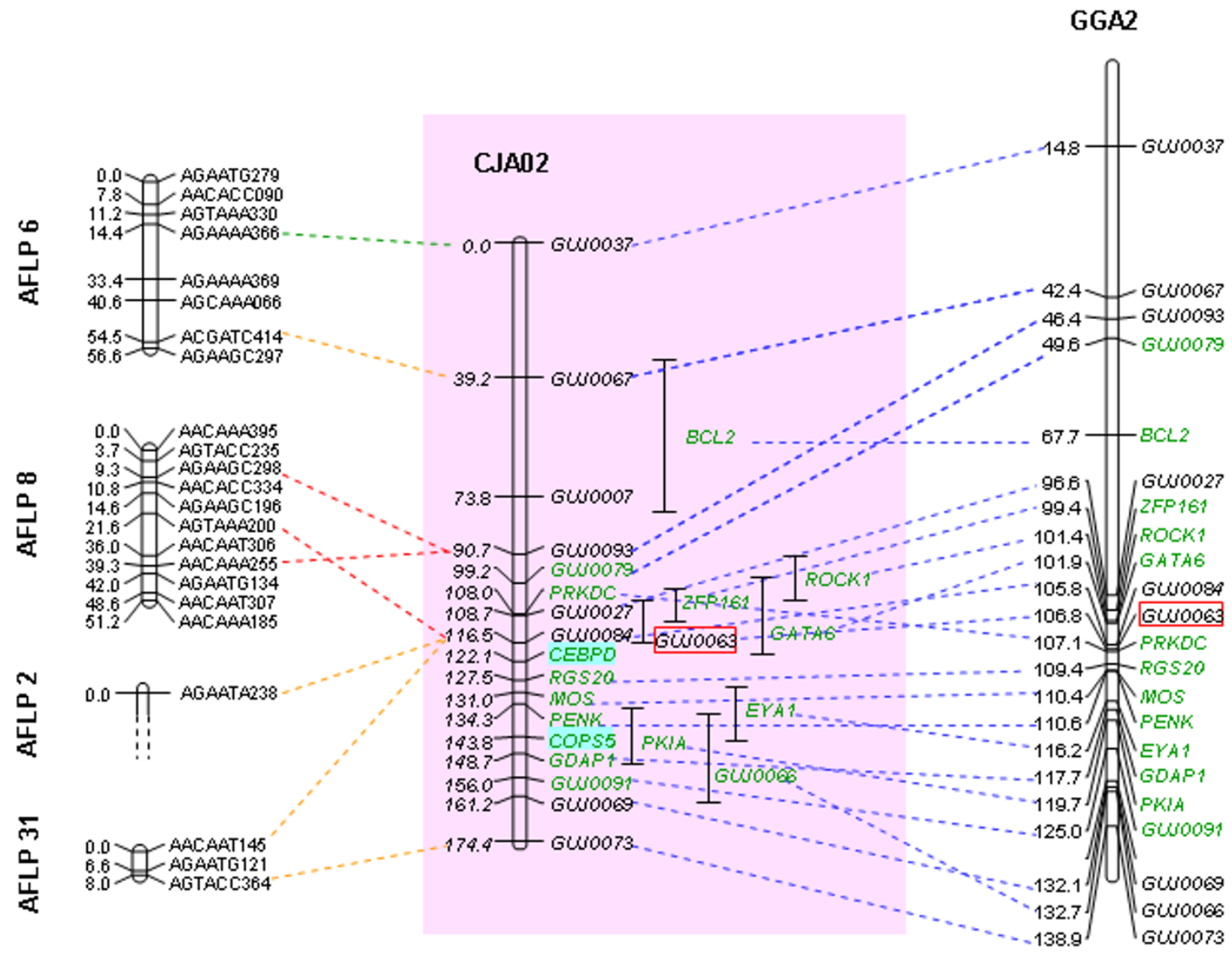

Figure 2

Alignments of Japanese quail microsatellite and AFLP maps and links to the assembled chicken sequence. Left: AFLP linkage groups from [14]; center: integrated microsatellite and gene map (this study); right: chicken February 2004 sequence assembly [22]. AFLP and microsatellite genetic maps are in cM and the sequence assembly is in Mb. New quail linkage groups have blue titles and new microsatellite and gene markers are in green. Genes are in boldface italic. Microsatellite markers informative in both species are in red boxes. Chicken markers have a yellow background. Quail microsatellites or genes with similarity to chicken sequence of unknown location (chrun) have a blue background. Dotted lines linking the microsatellite and the AFLP maps indicate positive results of two-point linkage between the markers, with supporting LOD scores of 3 to 6 (green), 6 to 10 (orange) or more than 10 (red).

two different microsatellite linkage groups. For example, the terminal marker of AFLP2 is linked to CJA02, whereas the rest of AFLP2 is linked to CJA03; likewise, AFLP8 has markers linked to CJA02 and CJA09.

\section{Alignment with the chicken sequence}

A BLASTN search of all the microsatellites on the quail map against the available chicken sequence assembly yielded significant hits for 61 out of 69 (88.4\%) of the quail-originated markers (Table 1) [see Additional file 1]. The remaining 8 markers had no hits. Sequence identities ranged from $63.6 \%$ to $100 \%$, alignment scores from 158 to 848 , and E-values from $43.1 \mathrm{E}-31$ to 2.8 . For a number of markers, a microsatellite, though sometimes interrupted or very short, could be found in the chicken sequence. All the Type I markers, except $A B C B 6$, which had no hit to the chicken genome sequence, produced significant hits, with E-values ranging from 8.90E-247 to 2.40E-17 (Table 2) [see Additional file 2]. These values reflect the high degree of sequence conservation between chicken and quail, especially for Type I markers. Although $A B C B 6$ had no direct hit to the chicken genome assembly, 


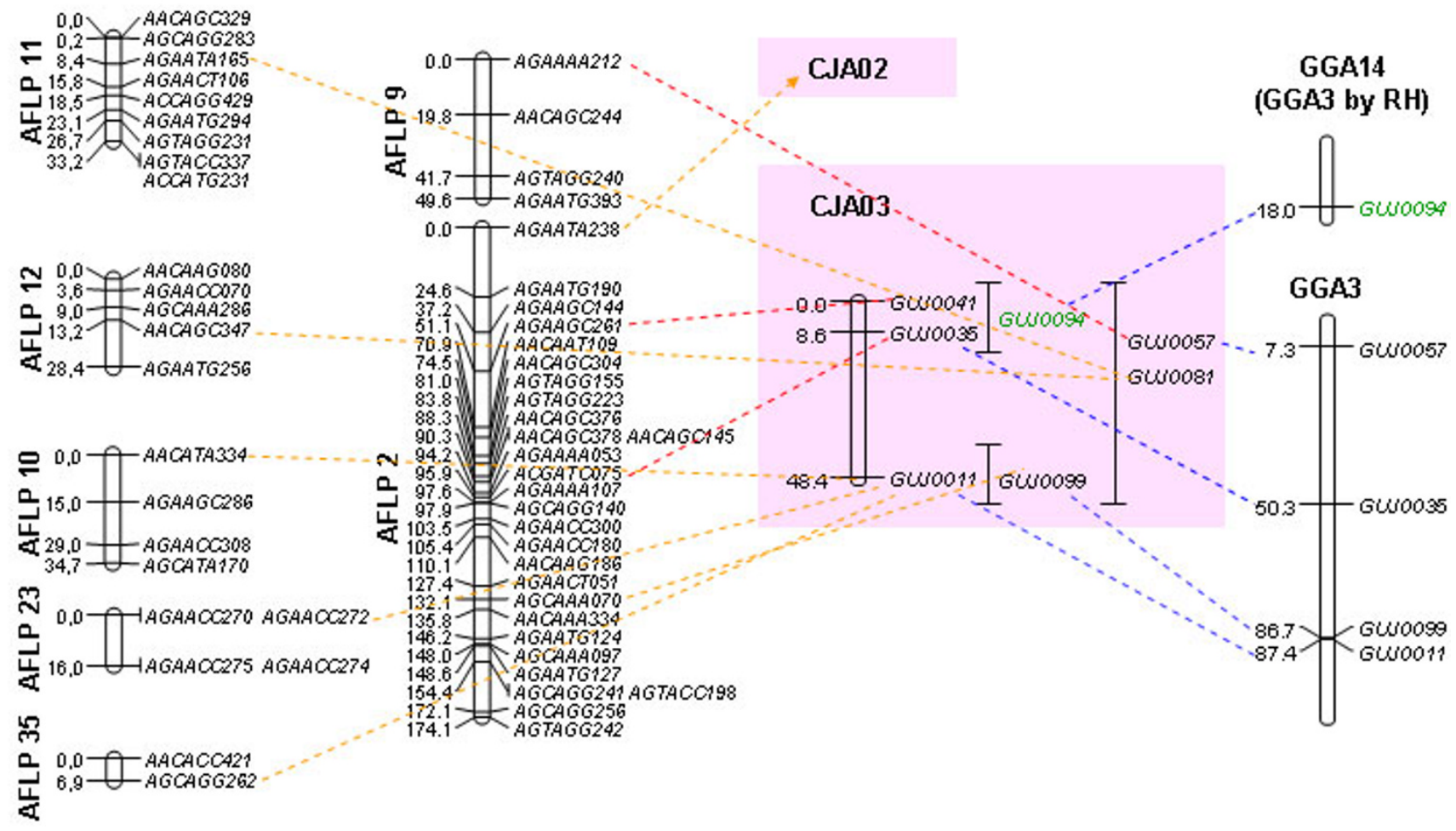

\section{Figure 3}

Alignments of Japanese quail microsatellite and AFLP maps and links to the assembled chicken sequence. Left: AFLP linkage groups from [14]; center: integrated microsatellite and gene map (this study); right: chicken February 2004 sequence assembly [22]. AFLP and microsatellite genetic maps are in cM and the sequence assembly is in Mb. New quail linkage groups have blue titles and new microsatellite and gene markers are in green. Genes are in boldface italic. Microsatellite markers informative in both species are in red boxes. Chicken markers have a yellow background. Quail microsatellites or genes with similarity to chicken sequence of unknown location (chrun) have a blue background. Dotted lines linking the microsatellite and the AFLP maps indicate positive results of two-point linkage between the markers, with supporting LOD scores of 3 to 6 (green), 6 to 10 (orange) or more than 10 (red).

it matches the chicken EST BI391579, which aligns with the genome assembly in the fraction of sequences not attributed to a chromosome (chrun) at $101.609 \mathrm{Mb}$.

A plot of the sequence coordinates of both Type I and Type II markers on the chicken sequence assembly enabled the alignments of the integrated quail maps with chicken chromosomes, thus permitting the correct orientation and assignment of all the quail linkage groups (Figure 1 to 8 ). These alignments revealed remarkable similarity in the order of markers between chicken and quail in both the macrochromosomes (CJA01-07) and the microchromosomes (CJA09, 10, 13, 14, 18, 20, 27).

Inconsistent marker order between the two species suggestive of local chromosomal inversions or of errors in one or the other dataset was observed on chromosomes 1,2 and 5. Linkage mapping has a lower resolution than the sequence assembly, but the latter may have portions of chromosomes in wrong places. It is therefore difficult to make a decision on marker order, especially as these rearrangements can be real local inversions. 

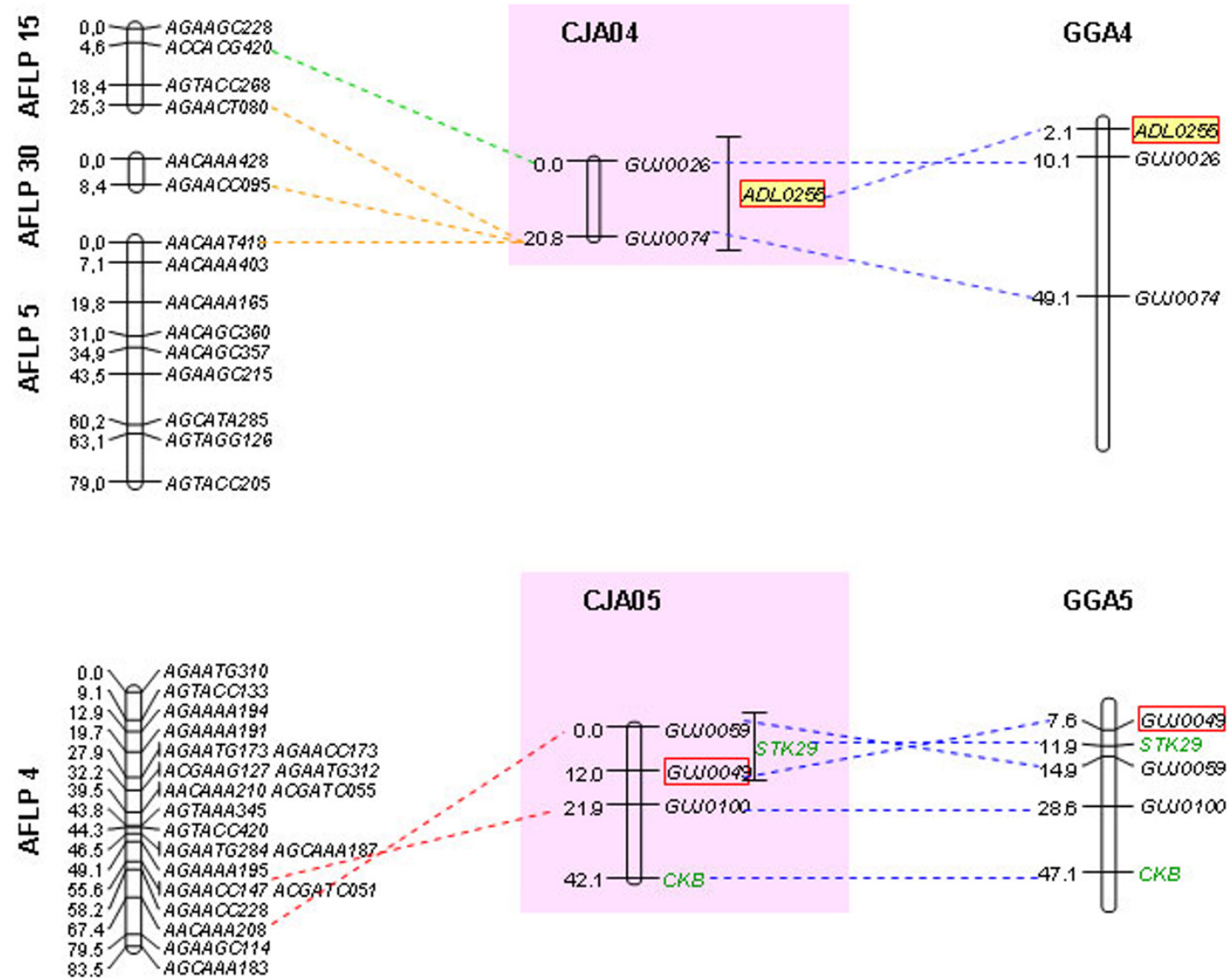

\section{Figure 4}

Alignments of Japanese quail microsatellite and AFLP maps and links to the assembled chicken sequence. Left: AFLP linkage groups from [14]; center: integrated microsatellite and gene map (this study); right: chicken February 2004 sequence assembly [22]. AFLP and microsatellite genetic maps are in cM and the sequence assembly is in Mb. New quail linkage groups have blue titles and new microsatellite and gene markers are in green. Genes are in boldface italic. Microsatellite markers informative in both species are in red boxes. Chicken markers have a yellow background. Quail microsatellites or genes with similarity to chicken sequence of unknown location (chrun) have a blue background. Dotted lines linking the microsatellite and the AFLP maps indicate positive results of two-point linkage between the markers, with supporting LOD scores of 3 to 6 (green), 6 to 10 (orange) or more than 10 (red).

All the markers present together on any of the quail linkage groups went together on a single chicken chromosome, with three notable exceptions in CJA03, CJA18 and CJAZ. The marker GUJ0094 from linkage group CJA03 indicated strong sequence similarity to GGA14 sequence at position $18 \mathrm{Mb}$. However, a comparative study between a RH map and the sequence assembly of GGA14 showed that the portion between 17 and $19.5 \mathrm{Mb}$ of the latter corresponds, in fact, to GGA3 [19]. In the case of CJA18 and CJAZ, the markers GUJ0039 and GUJ0025 showed strong sequence similarity to portions of GGA3_random and
GGA10_random, respectively. Considering that these markers were assigned to "improperly" assembled portions of the chromosomes designated as "random", we decided to investigate these discrepancies. Both GUJ0039 and GUJ0025 were genotyped on the ChickRH6 panel [20] and were found by two-point linkage analysis to cosegregate with markers belonging to GGA18 and GGAZ, respectively [21]. Thus, when correcting chicken sequence assembly errors by RH mapping, we find that all markers from a given quail linkage group correspond to one chicken chromosome. 

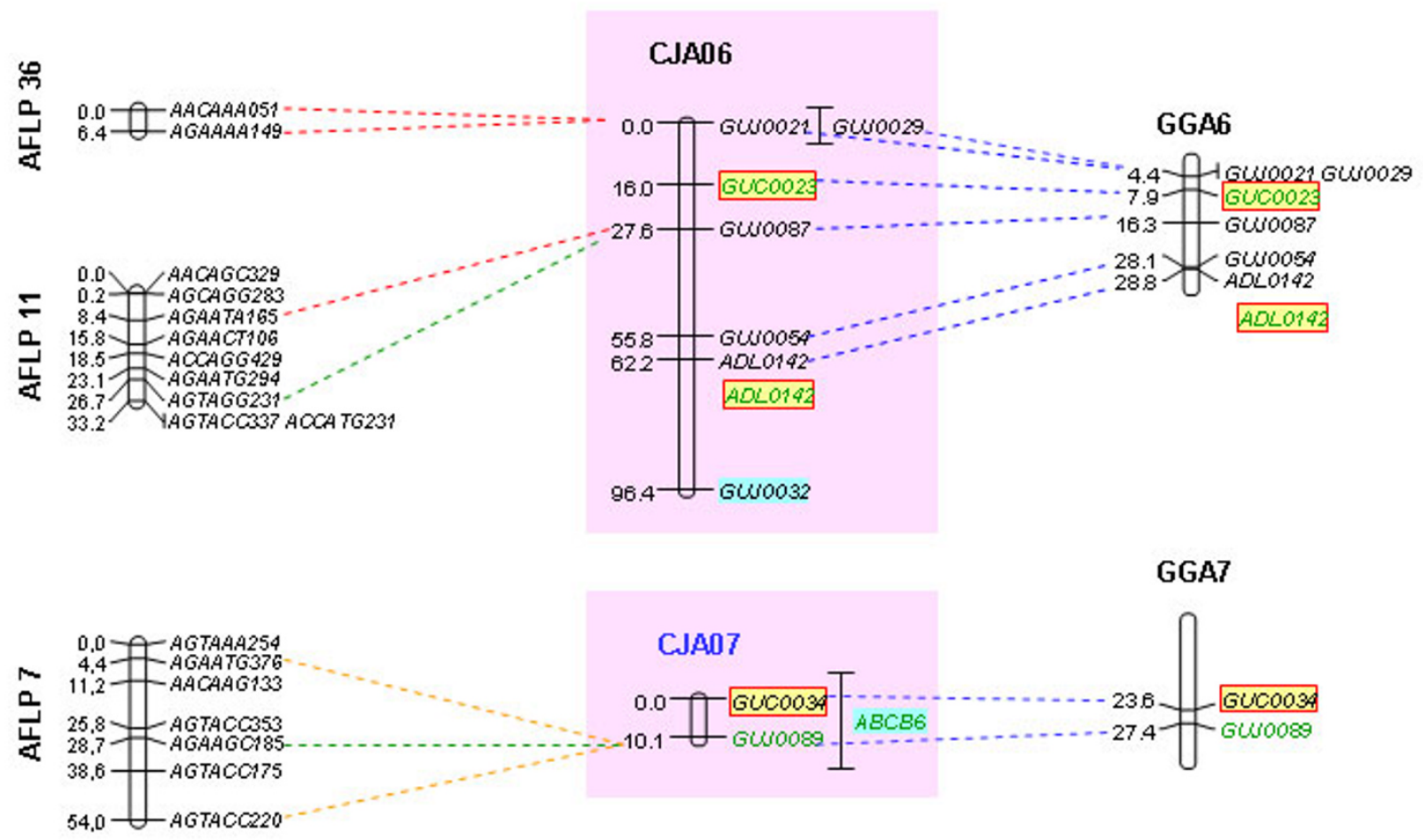

\section{Figure 5}

Alignments of Japanese quail microsatellite and AFLP maps and links to the assembled chicken sequence. Left: AFLP linkage groups from [14]; center: integrated microsatellite and gene map (this study); right: chicken February 2004 sequence assembly [22]. AFLP and microsatellite genetic maps are in cM and the sequence assembly is in Mb. New quail linkage groups have blue titles and new microsatellite and gene markers are in green. Genes are in boldface italic. Microsatellite markers informative in both species are in red boxes. Chicken markers have a yellow background. Quail microsatellites or genes with similarity to chicken sequence of unknown location (chrun) have a blue background. Dotted lines linking the microsatellite and the AFLP maps indicate positive results of two-point linkage between the markers, with supporting LOD scores of 3 to 6 (green), 6 to 10 (orange) or more than 10 (red).

\section{Comparative FISH studies}

All 49 chicken BAC clones tested for hybridization to quail metaphase chromosomes gave a positive FISH signal. The 29 clones from chicken macrochromosomes 1-8 and $\mathrm{Z}$ were found in almost the same order on their quail counterparts and only few differences suggesting centromeric inversions in chromosomes 1,2 and 4 could be detected (Table 3 and Figure 9). For chromosome 1, the markers P2-6 and B3H9 are both located on the p arm in chicken whereas in quail their positions are reversed: P26 is located on the $\mathrm{q}$ arm close to the centromere and
$\mathrm{B} 3 \mathrm{H} 9$ is found in the centromeric region. In chromosome 2, the markers B2B4 and bw107K17 are inverted between chicken and quail, while in chromosome 4 the marker bw8H20 on the p arm in chicken appears on the $\mathrm{q}$ arm in quail. All 20 BAC clones from chicken microchromosomes hybridized to microchromosomes in quail. For seven chicken microchromosomes, two clones were chosen as far as possible from one another on the corresponding genetic linkage groups, so as to ensure a good coverage. Such pairs of clones were analyzed simultaneously in dual-color FISH experiments. In all cases, clones 

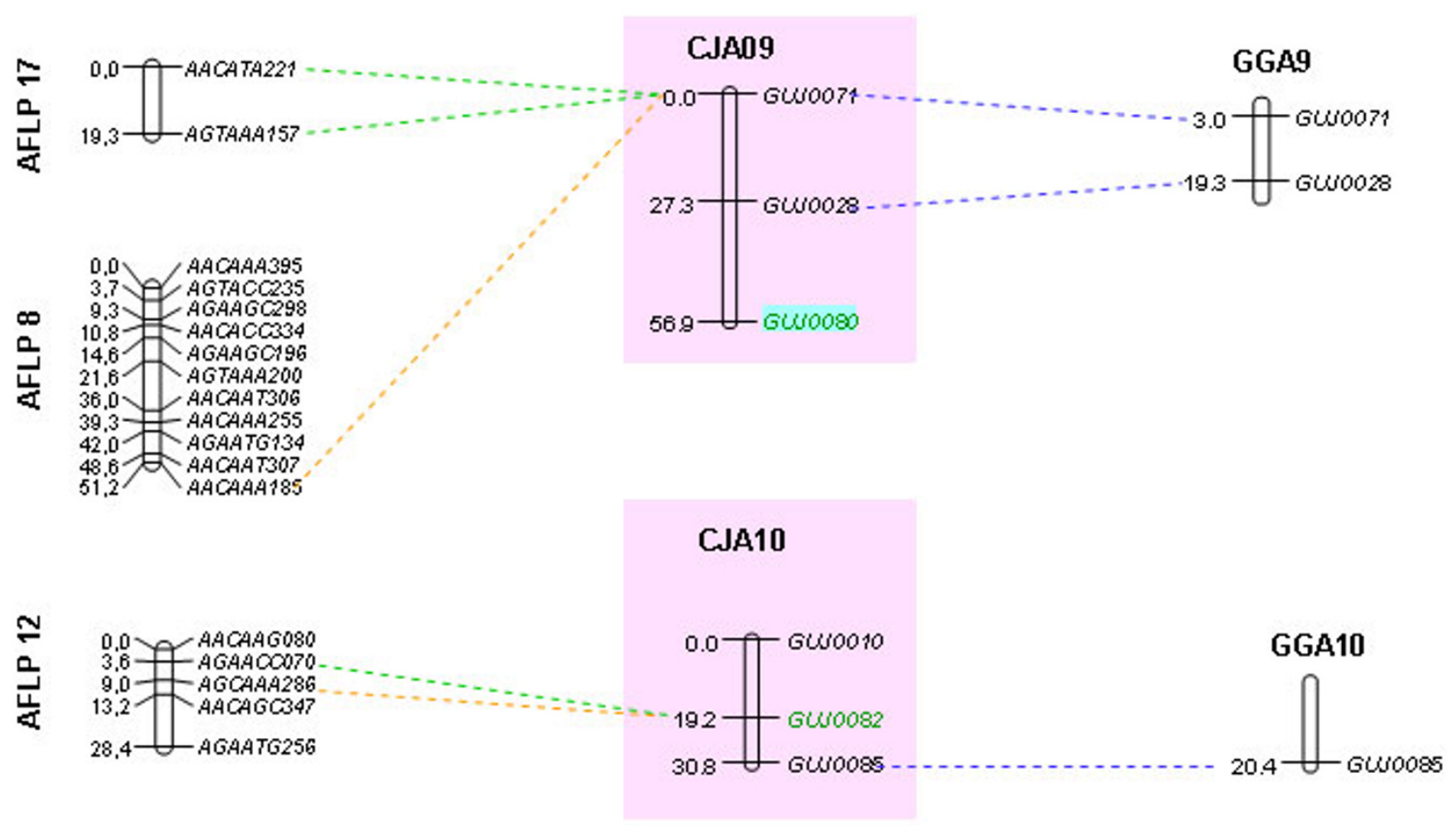

Figure 6

Alignments of Japanese quail microsatellite and AFLP maps and links to the assembled chicken sequence. Left: AFLP linkage groups from [14]; center: integrated microsatellite and gene map (this study); right: chicken February 2004 sequence assembly [22]. AFLP and microsatellite genetic maps are in cM and the sequence assembly is in Mb. New quail linkage groups have blue titles and new microsatellite and gene markers are in green. Genes are in boldface italic. Microsatellite markers informative in both species are in red boxes. Chicken markers have a yellow background. Quail microsatellites or genes with similarity to chicken sequence of unknown location (chrun) have a blue background. Dotted lines linking the microsatellite and the AFLP maps indicate positive results of two-point linkage between the markers, with supporting LOD scores of 3 to 6 (green), 6 to 10 (orange) or more than 10 (red).

co-hybridized to the same quail microchromosome, suggesting high conservation between both species. Altogether, 13 chicken microchromosomes were investigated, allowing identification of their quail counterparts.

\section{Discussion}

\section{Integrated maps for QTL studies}

To date, this is the most enhanced genetic linkage map presented for the Japanese quail. It is an improvement over the microsatellite linkage map of Kayang et al. (2004) [15], both in terms of marker number and quality, with a number of Type I loci added, and a wider coverage of the quail genome. An added value is the alignments with the AFLP linkage map of Roussot et al. (2003) [14], thus permitting the chromosomal assignment of 31 out of the 41 AFLP linkage groups. Neither of the two maps looks complete and the microsatellite map has a lower number of linkage groups than chromosomes, due to the difficulty in mapping the small microchromosomes. However, the microsatellite map appears to be a great improvement over the AFLP map, in which even the macrochromosomes appear to be fragmented into several linkage groups and some AFLP markers seem to be assigned to the wrong linkage group. This demonstrates the limits of using AFLP markers in a F2 cross between two lines that are only partially inbred. Nevertheless, the alignment of both maps is useful as it enables a comparison of the location of QTL found in the different crosses. For instance, the QTL on tonic immobility found on the AFLP linkage group 1 [16] can now be related to the suggestive QTL for the same trait found on CJA01 [17].

The majority of poultry (and indeed avian) genomic studies have focused on the chicken, culminating in the sequencing of its entire genome [22]. The slow pace of mapping in other poultry genomes primarily can be 


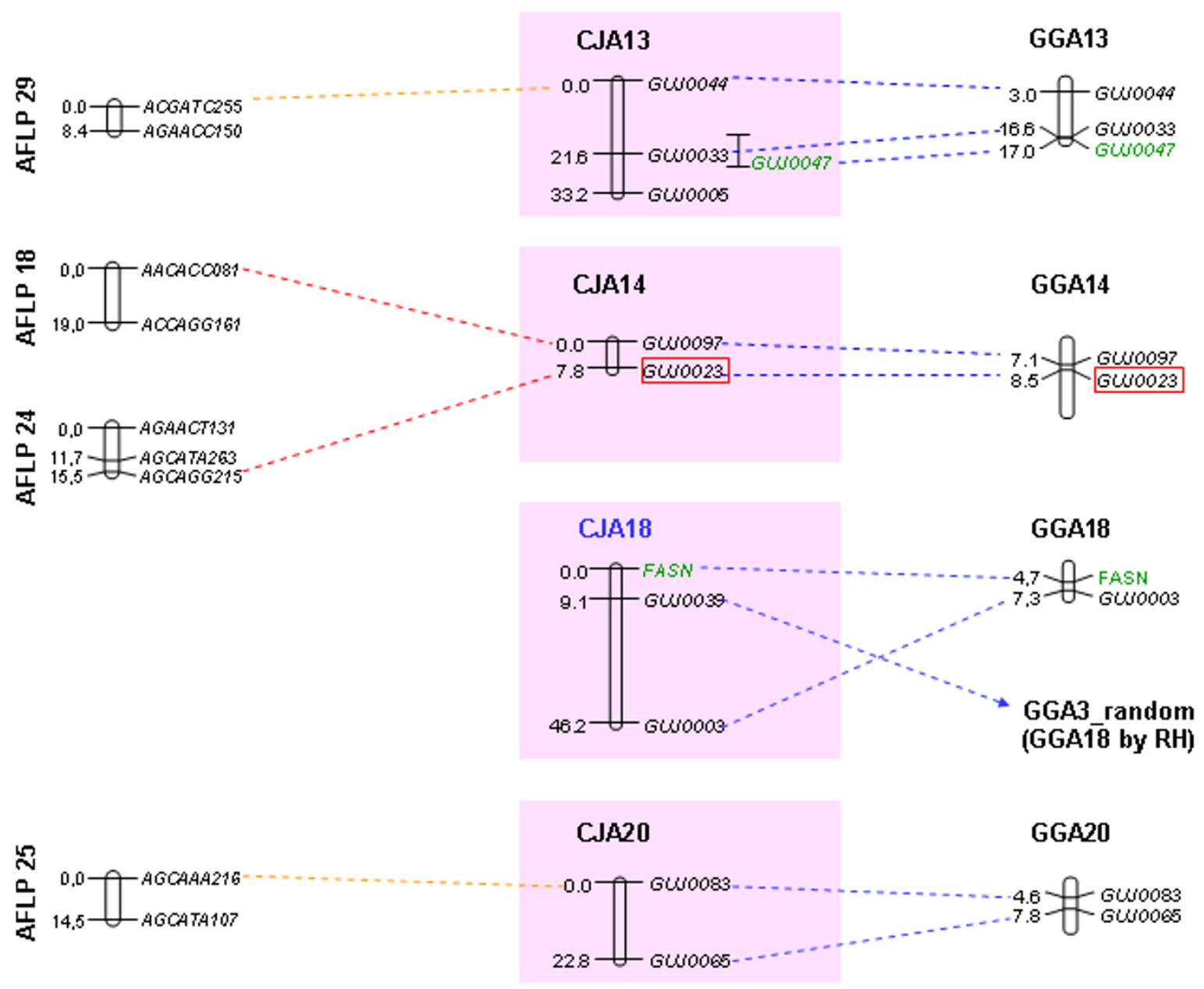

\section{Figure 7}

Alignments of Japanese quail microsatellite and AFLP maps and links to the assembled chicken sequence. Left: AFLP linkage groups from [14]; center: integrated microsatellite and gene map (this study); right: chicken February 2004 sequence assembly [22]. AFLP and microsatellite genetic maps are in cM and the sequence assembly is in Mb. New quail linkage groups have blue titles and new microsatellite and gene markers are in green. Genes are in boldface italic. Microsatellite markers informative in both species are in red boxes. Chicken markers have a yellow background. Quail microsatellites or genes with similarity to chicken sequence of unknown location (chrun) have a blue background. Dotted lines linking the microsatellite and the AFLP maps indicate positive results of two-point linkage between the markers, with supporting LOD scores of 3 to 6 (green), 6 to 10 (orange) or more than 10 (red).

attributed to the paucity of markers, particularly microsatellites, which are the markers of choice for genetic mapping and QTL detection, and also to the fact that only a few groups work on species other than chicken. Microsatellite markers are indeed difficult to develop in large numbers for poultry because of a relatively lower frequency of occurrence, when compared to mammals [23]. Chicken microsatellite markers could be a source for the development of the quail map, but there is a low success rate of cross-species amplification between the two species $[24,25]$. Studies by Primmer et al, (1996) [26] in passerine birds revealed a significant negative correlation between microsatellite performance and evolutionary distance between species, with $50 \%$ of the markers revealing polymorphism if the divergence between the original and the tested species is 11 million years. Thus, the success rate of chicken microsatellites in quail is expected to be lower, due to a divergence that goes back to 35 million years $[7,8]$. An alternative to microsatellites for genetic mapping is to use SNP. Our results demonstrate that the use of information on the sequence, the structure and the position of genes in the genome of chicken, is a good approach for a targeted development of SNP in a defined region in quail, in our case CJA02. 

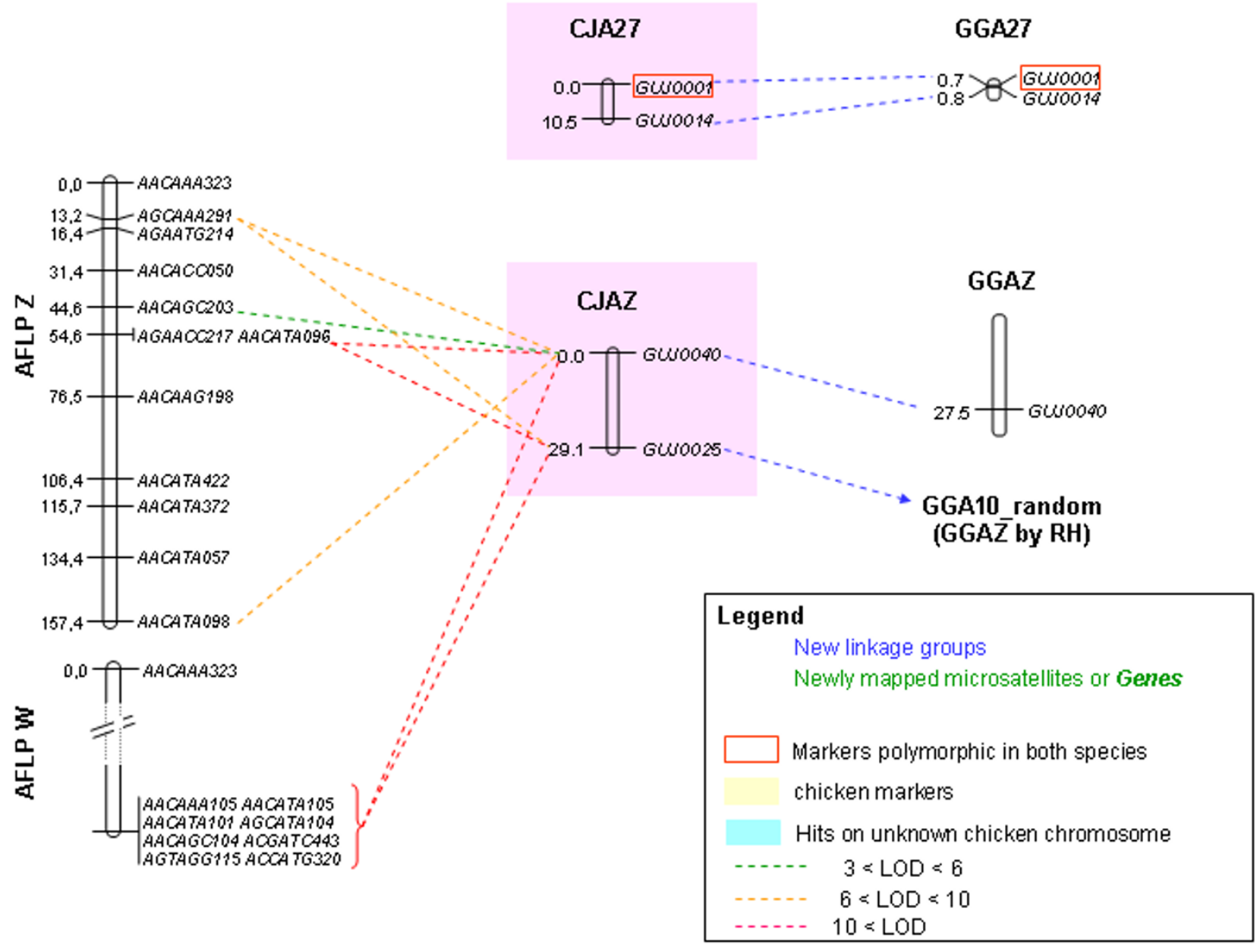

\section{Figure 8}

Alignments of Japanese quail microsatellite and AFLP maps and links to the assembled chicken sequence. Left: AFLP linkage groups from [14]; center: integrated microsatellite and gene map (this study); right: chicken February 2004 sequence assembly [22]. AFLP and microsatellite genetic maps are in cM and the sequence assembly is in Mb. New quail linkage groups have blue titles and new microsatellite and gene markers are in green. Genes are in boldface italic. Microsatellite markers informative in both species are in red boxes. Chicken markers have a yellow background. Quail microsatellites or genes with similarity to chicken sequence of unknown location (chrun) have a blue background. Dotted lines linking the microsatellite and the AFLP maps indicate positive results of two-point linkage between the markers, with supporting LOD scores of 3 to 6 (green), 6 to 10 (orange) or more than 10 (red).

Further compounding the situation in birds is the numerous indistinguishable microchromosomes. Thus, apart from the Japanese quail, preliminary genetic linkage maps have only been reported for the turkey $[27,28]$ but are yet to be published for most important poultry species. Given the difficulty in mapping avian genomes, this integrated map is a further boost to genomic studies in quail and is a valuable resource that will improve the localization of QTL for the commercial improvement of this species and will help its promotion as a laboratory model for poultry.

\section{Chromosome rearrangements since the divergence of quail} and chicken

Altogether, the genetic and FISH comparative maps revealed very high similarities in marker order between the two species both for the macrochromosome (CJA0108, CJAZ) and the microchromosome (CJA09, 10, 11, 13, $14,15,17,18,19,20,24,26,27,28)$ fractions of the genome. Therefore, all the syntenic segments investigated were conserved.

Several studies suggest a high stability of avian karyotypes, which is now well documented for macrochromosomes. 
Table I: Location of Japanese quail microsatellite markers from the genetic map on the chicken February 2004 genome assembly by BLASTN.

\begin{tabular}{|c|c|c|c|c|c|}
\hline Quail locus' & Origin & Linkage group & Position (cM) & Chicken Chr:Mb ${ }^{3}$ & E-value ${ }^{4}$ \\
\hline GUJ0090 & quail & CJAOI & 0 & chrl:24.420 & $2.3 \mathrm{E}-0 \mathrm{I}$ \\
\hline GUJ0068 & quail & CJAOI & 6 & $\operatorname{chrl}: 26.583$ & 2.9E-26 \\
\hline GUJ0062 & quail & CJAOI & 24 & chrl:37.77| & 2.0E-09 \\
\hline GUJ0098 & quail & CJAOI & 32 & chrl:43.072 & $2.5 \mathrm{E}-24$ \\
\hline GUJ00I 7 & quail & CJAOI & 39 & chrl:47.50I & $2.5 \mathrm{E}-17$ \\
\hline GUJ0036² & quail & CJAOI & 55 & chrl:40.563 & I.IE-II \\
\hline GUJ0077 & quail & CJAOI & 92 & chrl:76.184 & 6.IE-28 \\
\hline GUJ0056 & quail & CJAOI & 96 & chrl:77.75I & I.2E-05 \\
\hline GUJ00 I 3 & quail & CJAOI & 126 & no hit & - \\
\hline GUJ0006 & quail & CJAOI & 154 & chrl:122.564 & $4.9 \mathrm{E}-03$ \\
\hline GUJ0048 & quail & CJAOI & 161 & chrl:I22.564 & 1.7E-05 \\
\hline GUJ0050 & quail & CJAOI & 173 & chrl:127.92I & I.IE-09 \\
\hline GUJ005I & quail & CJAOI & 193 & chrl:I26.894 & $3.5 \mathrm{E}-10$ \\
\hline GUJ0078 & quail & CJAOI & 218 & chrl:133.776 & $2.0 \mathrm{E}-0 \mathrm{I}$ \\
\hline GUJ0052 & quail & CJAOI & 232 & no hit & - \\
\hline GUJ0055 & quail & CJAOI & 244 & chrl:I57.520 & $1.8 \mathrm{E}-06$ \\
\hline GUJOIOI & quail & CJAOI & \pm 232 & chrl:I56.040 & 2.IE-16 \\
\hline ADL0037 & chicken & CJAOI & \pm 126 & chrl:I04.907 & $3.2 \mathrm{E}-50$ \\
\hline GUJ00952 & quail & CJAOI & \pm 126 & chrl:100.7I7 & I. $4 \mathrm{E}-02$ \\
\hline GUJ00642 & quail & CJAOI & \pm 275 & chrl:184.395 & $6.6 \mathrm{E}-23$ \\
\hline GUJ0037 & quail & CJAO2 & 0 & chr2:14.772 & $1.3 \mathrm{E}-18$ \\
\hline GUJ0067 & quail & CJA02 & 39 & chr2:42.387 & 4.4E-04 \\
\hline GUJ0007 & quail & CJA02 & 74 & no hit & - \\
\hline GUJ0093 & quail & CJA02 & 91 & chr2:46.413 & $2.3 \mathrm{E}-03$ \\
\hline GUJ00792 & quail & CJAO2 & 99 & chr2:49.645 & $1.2 \mathrm{E}-0 \mathrm{I}$ \\
\hline GUJ0027 & quail & CJA02 & 109 & chr2:96.645 & 2.7E-09 \\
\hline GUJ0084 & quail & CJAO2 & 117 & chr2:105.833 & $4.5 \mathrm{E}-06$ \\
\hline GUJ009/2 & quail & CJAO2 & 156 & chr2:125.035 & $9.2 \mathrm{E}-14$ \\
\hline GUJ0069 & quail & CJA02 & 161 & chr2:|32.08| & I.IE-19 \\
\hline GUJ0073 & quail & CJA02 & 174 & chr2:138.92। & 8.3E-07 \\
\hline GUJ0063 & quail & CJAO2 & \pm 110 & chr2:106.842 & 4.9E-26 \\
\hline GUJ00662 & quail & CJA02 & \pm 150 & chr2:132.662 & 1.2E-07 \\
\hline GUJ004I & quail & CJA03 & 0 & no hit & - \\
\hline GUJ0035 & quail & CJA03 & 9 & chr3:50.291 & $3.5 \mathrm{E}-09$ \\
\hline GUJ00 II & quail & CJA03 & 48 & chr3:87.368 & $3.0 \mathrm{E}-05$ \\
\hline GUJ0057 & quail & CJAO3 & \pm 20 & chr3:7.343 & $5.6 \mathrm{E}-\mathrm{II}$ \\
\hline GUJ008I & quail & CJA03 & \pm 20 & no hit & - \\
\hline GUJ0099 & quail & CJA03 & \pm 48 & chr3:86.666 & $7.6 \mathrm{E}-25$ \\
\hline GUJ00942 & quail & CJAO3 & \pm 5 & chr|4:|8.036 & 2.9E-22 \\
\hline GUJ0026 & quail & CJA04 & 0 & chr4:10.067 & $2.8 \mathrm{E}+00$ \\
\hline GUJ0074 & quail & CJAO4 & 21 & chr4:49.11 6 & 3.IE-3I \\
\hline ADLO2552 & chicken & CJAO4 & \pm 10 & chr4:2.089 & $4.2 \mathrm{E}-54$ \\
\hline GUJ0059 & quail & CJA05 & 0 & chr5:14.850 & $3.2 \mathrm{E}-25$ \\
\hline GUJ0049 & quail & CJA05 & 12 & chr5:7.574 & $1.9 \mathrm{E}-21$ \\
\hline GUJOIOO & quail & CJA05 & 22 & chr5:28.592 & $1.6 \mathrm{E}-16$ \\
\hline GUJ002I & quail & CJA06 & 0 & chr6:4.398 & $1.9 \mathrm{E}-13$ \\
\hline GUCO0232 & chicken & CJA06 & 16 & chr6:7.890 & 2.4E-25 \\
\hline GUJ0087 & quail & CJA06 & 28 & chr6:16.277 & I.2E-II \\
\hline GUj0054 & quail & CJA06 & 56 & chr6:28.056 & $5.6 \mathrm{E}-07$ \\
\hline ADLO/42 & chicken & CJA06 & 62 & chr6:28.806 & I. $2 \mathrm{E}-40$ \\
\hline GUJ00322 & quail & CJA06 & 96 & chrun:4I.057 & I. $4 \mathrm{E}-04$ \\
\hline GUJ0029 & quail & CJA06 & \pm 0 & chr6:4.398 & $2.4 \mathrm{E}-12$ \\
\hline GUC00342 & chicken & CJA07 & 0 & chr7:23.564 & $6.5 \mathrm{E}-1 \mathrm{I}$ \\
\hline GUJ00892 & quail & CJA07 & 10 & chr7:27.428 & 1.7E-05 \\
\hline GUJ007I & quail & CJA09 & 0 & chr9:3.000 & $8.4 \mathrm{E}-13$ \\
\hline GUJ0028 & quail & CJA09 & 27 & chr9:19.28| & 2.5E-II \\
\hline GUJ00802 & quail & CJA09 & 57 & chrun:0.025 & I.IE+00 \\
\hline GUJ00IO & quail & CJAIO & 0 & no hit & - \\
\hline
\end{tabular}


Table I: Location of Japanese quail microsatellite markers from the genetic map on the chicken February 2004 genome assembly by BLASTN. (Continued)

\begin{tabular}{|c|c|c|c|c|c|}
\hline GUJ00822 & quail & CJAI0 & 19 & no hit & - \\
\hline GUJ0085 & quail & CJAIO & 31 & chrl0:20.429 & $1.6 \mathrm{E}-19$ \\
\hline GUJ0044 & quail & CJAI3 & 0 & chrl3:3.033 & $6.7 \mathrm{E}-16$ \\
\hline GUJ0033 & quail & CJAI3 & 22 & chrI3:16.646 & I.OE-II \\
\hline GUJ0005 & quail & CJAI3 & 33 & no hit & - \\
\hline GUJ00472 & quail & CJAI3 & \pm 22 & chr|3:17.033 & $5.5 \mathrm{E}-28$ \\
\hline GUJ0097 & quail & CJAI4 & 0 & chrl4:7.106 & 5.7E-09 \\
\hline GUJ0023 & quail & CJAI4 & 8 & chr |4:8.487 & $4.4 \mathrm{E}-15$ \\
\hline GUJ0039 & quail & CJAI8 & 9 & chr3_random & $2.6 \mathrm{E}-13$ \\
\hline GUJ0003 & quail & CJAI8 & 46 & chrl8:7.342 & I.3E-II \\
\hline GUJ0083 & quail & CJA20 & 0 & chr20:4.643 & $2.6 \mathrm{E}-02$ \\
\hline GUJ0065 & quail & CJA2O & 23 & chr20:7.845 & $7.9 \mathrm{E}-06$ \\
\hline GUJ000I & quail & CJA27 & 0 & chr27:0.677 & $4.5 \mathrm{E}-25$ \\
\hline GUJ00 I 4 & quail & CJA27 & 11 & chr27:0.750 & I.5E-07 \\
\hline GUJ0040 & quail & CJAZ & 0 & chrZ:27.527 & $1.3 \mathrm{E}-16$ \\
\hline GUJ0025 & quail & CJAZ & 29 & chrl0_random & 2.4E-2I \\
\hline
\end{tabular}

IGUJ markers were developed by Kayang et al. $(2000,2002)$ [37, 38], GUC markers were developed by Kayang et al (2003) [53], ADL markers were developed by Cheng and Crittenden (1994) [54]; Cheng et al. (1995) [55].

${ }^{2}$ Newly mapped microsatellites

3Position of the quail microsatellite sequence on the chicken genome sequence assembly, determined by BLASTN

${ }^{4} \mathrm{E}$-value of the quail-chicken alignment

\pm indicates the median position of non-framework markers Chrun: chicken genomic sequence of unknown location. Chr_random: chicken genomic sequence assigned to, but not located on a chromosome.

The karyotype of most bird orders usually share characteristic features, such as relatively high chromosome numbers $(76 \leq 2 n \leq 84)$, the presence of few macrochromosomes and numerous morphologically indistinguishable microchromosomes, and $\mathrm{ZZ/ZW}$ sex chromosomes. Comparative analyses of macrochromosomes for several bird species by using chicken whole chromosome painting probes in cross-species experiments have shown a low degree of inter-chromosomal rearrangements $[29,30]$. The high degree of sequence

Table 2: Location by BLASTN of quail genetic map Type I markers on the chicken genome assembly

\begin{tabular}{|c|c|c|c|c|c|c|c|}
\hline Marker & Genel & Chicken chr. ${ }^{2}$ & $\begin{array}{l}\text { Fragment } \\
\text { Position }^{3}\end{array}$ & Size (bp) & Quail LG4 & $\begin{array}{l}\text { Chicken } \\
\text { Chr:Mb }\end{array}$ & E-value 6 \\
\hline GCTII2I & $A B C B 6$ & 7 & intron 9 & 113 & CJA07 & No hit ${ }^{7}$ & - \\
\hline GCTI 333 & $B C L 2$ & 2 & exon I & 237 & CJA02 & Chr2:67.684 & $2,00 \mathrm{E}-118$ \\
\hline GCTII 85 & CEBPD & 2 & 3' NC & 184 & CJA02 & Chrun:70.609 & $8,50 \mathrm{E}-22$ \\
\hline GCTI 297 & $C K B$ & 5 & intron 2 & 529 & CJA05 & Chr5:47.1I5 & $1,70 \mathrm{E}-129$ \\
\hline GCTI 1253 & COPS5 & 2 & exon 7 & 119 & $\mathrm{CJAO2}$ & Chrun: 12.590 & $5,30 \mathrm{E}-27$ \\
\hline GCTII 68 & EYAI & 2 & intron 15 & 492 & CJAO2 & Chr2:1 I6.158 & $2,40 \mathrm{E}-174$ \\
\hline GCTI820 & FASN & 18 & 3' NC & 623 & CJAI8 & Chrl8:4.745 & I,40E-229 \\
\hline GCTI 237 & GATA6 & 2 & intron 4 & 170 & CJA02 & Chr2:I01.86I & $9,60 \mathrm{E}-49$ \\
\hline GCTII70 & GDAPI & 2 & exon 3 & 110 & CJA02 & Chr2:117.706 & $2,40 \mathrm{E}-17$ \\
\hline EXT0006 & MOS & 2 & coding & 468 & CJA02 & Chr2:I10.417 & $1,90 E-216$ \\
\hline GCTII 80 & PENK & 2 & exon 2 & 314 & CJA02 & Chr2:I I0.572 & $1,60 \mathrm{E}-162$ \\
\hline GCTII73 & PKIA & 2 & 3' NC & 173 & CJA02 & Chr2:I19.680 & $8,60 \mathrm{E}-65$ \\
\hline EXT0007 & PRKDC & 2 & intron 12 & 786 & CJA02 & Chr2:107.114 & $2,20 \mathrm{E}-187$ \\
\hline GCTII 62 & RGS20 & 2 & 3' NC & 244 & CJA02 & Chr2:109.426 & $5,90 \mathrm{E}-78$ \\
\hline GCTI 233 & ROCKI & 2 & intron30 & 179 & CJA02 & Chr2:101.378 & $3,30 \mathrm{E}-40$ \\
\hline GCTI399 & STK29 & 5 & intron 14 & 804 & CJA05 & Chr5:II.889 & $8,90 \mathrm{E}-247$ \\
\hline GCTI40I & $T Y R$ & 1 & Exon 2 & 188 & CJAOI & Chrl:I 79.594 & $3,30 \mathrm{E}-84$ \\
\hline EXT0004 & ZFPI6I & 2 & microsatellite & 224 & $\mathrm{CJAO2}$ & Chr2:99.35I & $4,50 \mathrm{E}-8 \mathrm{I}$ \\
\hline
\end{tabular}

ICorresponds to the gene name assigned by ICCARE to the chicken EST from which the primers were designed

2Determined by $\mathrm{RH}$ mapping [2I].

${ }^{3}$ Determined by analogy to the orthologous human gene by ICCARE

${ }^{4}$ Linkage group

${ }^{5}$ Position of the quail fragment on the chicken genome sequence assembly, determined by BLASTN

${ }^{6} \mathrm{E}$-value of the quail-chicken alignment

${ }^{7}$ GCTI I2I has a significant hit with chicken EST BI39|579, that aligns with the chicken assembly at chrun:101609|3|-101609680 
Table 3: FISH mapping quail small macrochromosomes and microchromosomes with chicken BAC clones

\begin{tabular}{|c|c|c|c|c|}
\hline Chicken chromosome & BAC clones & Chicken genetic markers & Chicken genetic map (cM) & $\begin{array}{c}\text { Quail chromosome or size } \\
\text { estimate }\end{array}$ \\
\hline $6 q 11$ & bw27G 19 & LEI0192 & 31 & 6qcen \\
\hline $7 p 12$ & bw69P2I & LEI0064 & 0 & 7qcen \\
\hline $7 q \mid 3-q 14$ & bw $27 C 3$ & MCW020I & 79 & 7qter \\
\hline $7 q 15-q 16$ & bw26MI6 & ADL0169 & 165 & $7 q$ ter and $8 q$ ter 1 \\
\hline $7 q 16$ & P4G2 & no & - & $7 q$ \\
\hline $8 p / 2$ & bw29CI7 & MCW0275 & 6 & $8 q$ \\
\hline $8 q 14$ & bw40L3 & LEI0044 & 96 & 8qter \\
\hline 9 & PIA6 & GCT00I6 & 41 & 9 \\
\hline 9 & bw $14 A 21$ & MCW0I34 & 132 & 9 \\
\hline 10 & bw8G I0 & MCW0I32 & 88 & 10 \\
\hline 11 & bw35FI5 & LEI0I43 & 0 & 11 \\
\hline 11 & bw29LI0 & MCW0097 & 18 & 11 \\
\hline 13 & bwI4GI2 & MCW0244 & 0 & 8 \\
\hline 13 & bw $35 C 23$ & MCW0I04 & 74 & 8 \\
\hline 14 & bw43B20 & MCW0296 & 0 & $11-14$ \\
\hline 14 & bw32N20 & MCW0225-NTN2 & 77 & $11-14$ \\
\hline 15 & bw3B7 & ADL0206 & 0 & $13-16$ \\
\hline 15 & bw7GI & MCW02II & 49 & $13-16$ \\
\hline 17 & $\mathrm{P} 5 \mathrm{HI} 2$ & no & - & $16-17$ \\
\hline 18 & bw $19 B \mid 3$ & MCW0045 & 0 & $16-18$ \\
\hline 18 & bwID2 & MCW0219 & 47 & $16-18$ \\
\hline 19 & P7E4 & no & - & $17-18$ \\
\hline 24 & bw2IH8 & MCW030I & 48 & $<30$ \\
\hline 26 & P2-7 & GCT0906 & 67 & $21-24$ \\
\hline 27 & bw9E8 & MCW0I46 & 35 & $23-25$ \\
\hline 28 & bw36G5 & LEI0I35 & 0 & 17 \\
\hline 28 & bw32P6 & ADL0299 & 60 & 17 \\
\hline
\end{tabular}

IThis BAC clone hybridizes to I chicken and 2 quail chromosomes

identity and similarities in marker order revealed by the comparative mapping with chicken performed in the present study demonstrates that the intra-chromosomic rearrangements are also rare. However, it is not impossible that some of the differences found in marker order between the quail and chicken maps presented here may be due to the lack of precision in marker ordering on the quail genetic map or errors in the chicken genome sequence assembly. The cytogenetic data shows that the rearrangements on chromosomes 1,2 and 4 all involve a change in the position of the centromere (Figure 9), thereby confirming similar findings by Shibusawa et al. (2001) [9]. Until now, all FISH studies on microchromosomes proved a strong conservation of synteny, with hybridization to chromosomes of similar sizes. For all 23 chromosomes investigated, no interchromosomal rearrangements could be detected. Although it is difficult to estimate the degree of coverage of microchromosomes in 


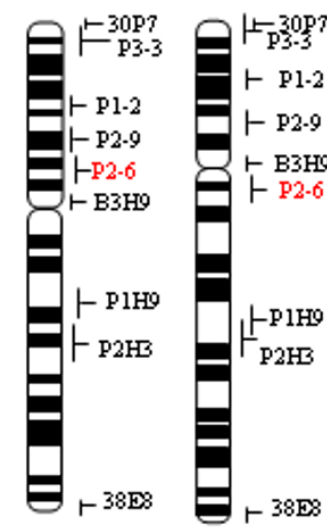

GGAl

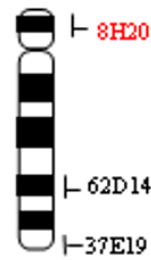

GGA4

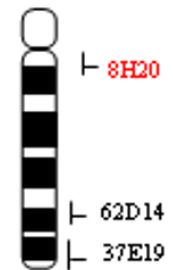

CJA4

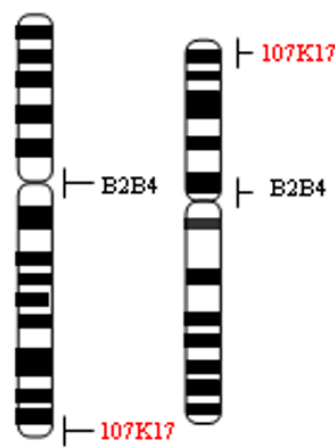

GGA2

CJA2
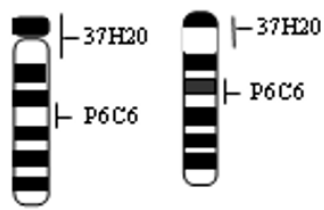

GGA5

CJA5

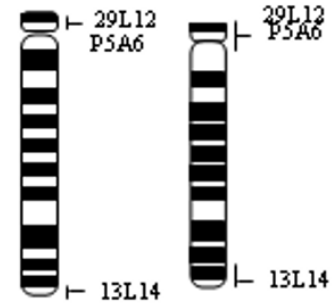

GGA3 CJA3

\section{Figure 9}

FISH of chicken macrochromosome BAC clones to quail chromosomes. Standard chicken and quail G-banding ideograms are from [52]. Markers mapped to different positions in both species are in red. Results on smaller macrochromosomes and microchromosomes are reported in Table 3.

our study, for seven of the microchromosomes, BAC clones were chosen from the ends of the chicken genetic linkage group, to maximize the chances of detecting interchromosomal rearrangements. The time of divergence between chicken and quail is estimated to be 35 million years $[7,8]$. Similar times of divergence can be found between humans and New World monkeys (35 million years) or humans and Old World monkeys (30 million years) [31], for which numerous interchromosomal events have been documented [32,33]. This suggests a higher stability of karyotypes in galliformes than in primates.

\section{Genome coverage by the microsatellite map}

An important point when building genetic maps is to estimate the degree of genome coverage within the linkage groups. As described above, the integrated map comprises
15 linkage groups spanning $904.3 \mathrm{cM}$ and 20 unlinked markers. CJA08, CJAW and 23 microchromosomes are still missing. It is quite probable that the unlinked markers belong to these chromosomes. This is not surprising as even in chicken, the genetic map and the sequence assembly for a number of microchromosomes are far from being complete. Assuming $50 \mathrm{cM}$ for each unlinked marker, the total map distance would be $1,904 \mathrm{cM}$. If the genome size of quail is comparable to that of chicken $(3,800 \mathrm{cM})$, then the comprehensive map represents $50 \%$ of the quail genome. Indeed, apart from chromosome 8, all the macrochromosomes are represented and the marker coverage and density for chromosomes 1 and 2 in particular, are high enough to permit the localization of QTL. Moreover, the presence of functional genes in the linkage groups, especially in CJA02, would be useful for comparative mapping and evolutionary studies. 


\section{Conclusion}

We have presented here the most comprehensive quail map to date, obtained by aligning all microsatellite data with the AFLP map and comparing it with the chicken sequence. These results together with our FISH experiments confirm the high level of synteny conservation between the two species. The availability of a comparative map between quail and chicken will accelerate mapping studies in quail not only by facilitating the transfer of genetic information in the form of markers but also gene predictions directly from chicken to quail. The level of detail is sufficient to allow the mapping of QTL, but subsequent efforts should aim at covering the missing parts of the genome by taking advantage of the sequenced chicken genome. Also, further integration of data and markers from one other group [34] should be pursued.

\section{Methods \\ Quail resource populations}

Three Japanese quail populations were used in this study: two established at INRA experimental units in Nouzilly, France and one developed at Gifu University, Gifu, Japan. Pop 1 was derived from two quail lines of the same genetic origin that had been divergently selected for short (STI) or long (LTI) duration of tonic immobility, a fear-related behavior trait [16]. Pop2 was derived from two quail lines of different genetic origins: line LTI selected for fearfulness and line DD selected for early egg production [35]. Pop3 consisted of 193 F2 individuals from 25 full-sib families derived from crosses between the wild-type and four plumage color mutant lines: silver $(B)$, black at hatch $(B h)$, extended brown $(E)$, and yellow $(Y)$. Ten of these families also carried the celadon eggshell color mutation (ce) [36]. The comprehensive map was, therefore, based on the genotyping results of a total of 1,050 quail from the three resource populations.

\section{Microsatellite (Type II) markers}

Most microsatellite markers used in this study were of quail origin. These included 82 previously published markers [37,38] and two new ones: GUJ0101 (GAGTGATAGGCTGAGAAAAC ; GCTTACCTATGTTCAGCTTG) and GUJ0102 (CTGGTAACTTCTTGCAGCCA ; GCTATAAGAAAGCACGGGAG) with respective GenBank accession numbers $\underline{\mathrm{AB} 181537}$ and $\mathrm{AB} 181538$. In addition, six chicken markers (ADL0037, ADL0142, ADL0255, GUC0023, GUC0028, and GUC0034) that cross-amplify quail DNA, reveal several alleles and are orthologous to the quail loci, were also included.

\section{Functional gene (Type I) marker development}

Most of the primers for Type I markers (Table 2) were chosen from chicken EST data aligned to the human sequence using the ICCARE (Interspecific Comparative Clustering and Annotation foR EST) web server [39]. This strategy enables one to predict the position of markers in chicken, through known synteny conservation data with human. Primers were chosen in exons for increasing cross-species PCR success rate, taking care to include small introns for maximizing chances of finding SNP. Finally, primer sequences were designed using the PRIMER3 server [40].

PCR of microsatellite markers were carried out in Pop2 as previously described [15]. In Pop1, PCR amplifications were carried out in $10 \mu \mathrm{l}$ reaction mixtures containing 15 ng of genomic DNA, $0.3 \mu \mathrm{M}$ of forward and reverse primers, $100 \mu \mathrm{M}$ of each dNTP, 1.5 to $2.5 \mathrm{mM} \mathrm{MgCl}_{2}$ as determined by test experiments, $0.5 \mathrm{U}$ Taq polymerase (Invitrogen Life Technologies, CA, USA) and $1 \mathrm{X}$ buffer (Invitrogen). The reverse primers were pre-labelled with fluorescent dyes: 6-FAM, HEX or NED fluorophores for automated genotyping. After an initial incubation for 5 min at $94^{\circ} \mathrm{C}, 30$ PCR cycles of $30 \mathrm{sec}$ at $94^{\circ} \mathrm{C}, 30 \mathrm{sec}$ at annealing temperature and $30 \mathrm{sec}$ at $72^{\circ} \mathrm{C}$ were performed, with a final elongation step at $72^{\circ} \mathrm{C}$ for $10 \mathrm{~min}$.

PCR amplifications of gene markers were performed in 25 $\mu \mathrm{l}$ reaction mixtures containing $25 \mathrm{ng}$ of genomic DNA, $0.2 \mu \mathrm{M}$ of forward and reverse primers, $200 \mu \mathrm{M}$ of each dNTP, $2 \mathrm{mM} \mathrm{MgCl}_{2}, 0.5 \mathrm{U}$ Taq DNA polymerase (Invitrogen) and $1 \mathrm{X}$ Invitrogen PCR buffer. The PCR cycling conditions were identical to those used for the microsatellite markers. PCR product sizes were determined by electrophoresis on $2 \%$ agarose gels in $1 \mathrm{X}$ Tris-Borate-EDTA (TBE) buffer for $30 \mathrm{~min}$ at $200 \mathrm{~V}$ in the presence of $5 \mu \mathrm{l}$ of Smart Ladder DNA size standard (Eurogentec, Seraing, Belgium). The gels were stained with ethidium bromide and visualized under UV light.

\section{Sequencing}

Quail gene marker PCR products were purified with the QIAquick PCR Purification Kit (Qiagen, Valencia, CA, USA) and cycle sequencing reactions were performed in $10 \mu \mathrm{l}$ with 10 to $20 \mathrm{ng}$ DNA, $10 \mathrm{pmol}$ of one of the PCR primers, and $2 \mu \mathrm{l}$ of Big Dye Terminator Mix (Applied Biosystems, Foster City, CA, USA). After an initial denaturation at $94^{\circ} \mathrm{C}$ for $5 \mathrm{~min}, 25$ PCR cycles of $30 \mathrm{sec}$ at $94^{\circ} \mathrm{C}$, $15 \mathrm{sec}$ at the annealing temperature and $4 \mathrm{~min}$ at $60^{\circ} \mathrm{C}$ were carried out. The products were then purified with the QIAquick Kit (Quiagen) and analyzed on an ABI Prism 3700 DNA Sequencer (Applied Biosystems). The identity of each gene was checked by sequence comparison with the chicken EST.

\section{Genotyping}

Microsatellite PCR products were combined into sets of 3 to 8 markers according to size and dye color compatibility, electrophoresed on ABI Prism 3100 or 3700 DNA Sequencers (Applied Biosystems) and sized using Genescan version 3.7 software (Applied Biosystems). Genotyp- 
ing analysis was performed using Genotyper version 3.7 software (Applied Biosystems).

Detection of polymorphism and genotyping of Type I markers were done on Pop 1 by SSCP analysis. PCR products were denatured at $94^{\circ} \mathrm{C}$ for $5 \mathrm{~min}$ and loaded on a $10 \%$ polyacrylamide gel (acrylamide: bisacrylamide 49:1), containing 5\% glycerol. Electrophoresis was run at $15^{\circ} \mathrm{C}$ between 400 and $700 \mathrm{~V}$ for 14 to $24 \mathrm{~h}$ depending on the size of the fragment being analyzed. The results were visualized by $\mathrm{AgNO}_{3}$ staining [41]. Each marker was first tested on the F1 individuals of Pop1 to detect polymorphism before genotyping the whole population.

\section{Linkage analysis and map construction}

Linkage analysis was performed using CriMap version 2.4 software [42]. Correct Mendelian inheritance of marker alleles was checked with the PREPARE option. Discordant data was rechecked within Genotyper and if no correction was possible, individuals were retyped. A two-point linkage analysis of all the markers was then computed using a LOD score threshold of 3.0 to assign markers to linkage groups. Subsequently, the BUILD option was used to order markers within each linkage group. Two or three loci with the highest number of informative meioses were chosen as the ordered loci and additional markers in the group were sequentially incorporated one by one at every possible location. At each step, the likelihood of the order was computed and the order with the maximum likelihood was retained. The process ended when no more markers could be inserted. Finally, the FLIPS option was used to examine the order of the different loci within each linkage group by inverting every two or three loci, thus verifying the robustness of the linkage groups and eventually finding the best order. Map distances were derived based on the Kosambi mapping function and the maps were drawn using MapChart version 2.0 [43].

\section{FISH under heterologous conditions}

Large-insert clones for FISH mapping were from two different BAC libraries and one PAC library $[44,45]$. Clones for heterologous FISH mapping in quail were selected according to their known position in chicken, as determined by FISH or by genetic mapping of a microsatellite or SSCP marker [46-48].

Quail metaphase spreads were obtained from seven-day old embryo fibroblast cultures arrested 4 hours with 0.06 $\mu \mathrm{g} / \mathrm{ml}$ colcemid (Gibco BRL, Grand Island, NY) and fixed by standard procedures.

For single color FISH, 100 ng of clone DNA were labelled by random priming using biotin-16-dUTP (BoehringerMannheim, Mannheim, Germany). Probes were then hybridized in situ for 48 hours in a hybridization buffer containing $30 \%$ formamide, after which the slides were washed in $40 \%$ formamide at $42{ }^{\circ} \mathrm{C}$, followed by detections with avidin-fluorescein isothiocyanate (FITC) (Vector Laboratories Inc., Burlingame, CA). Chromosomes were counterstained with propidium iodide (Sigma Chemical Co., St Louis, MO) in antifade solution (Vector) [49].

Two-color FISH was performed using a total of 20 chicken clones for localization on quail microchromosomes (Table 3). Labelling was done with digoxigenin (digoxigenin-11-dUTP, Boehringer-Mannheim) or biotin (biotin-16-dUTP, Boehringer-Mannheim). Biotinlabelled probes were detected with avidin-texas red (Vector) and digoxigenin-labelled ones with FITC antibodies (Boehringer-Mannheim). Chromosomes were counterstained with DAPI (4', 6-diamidino-2-phenilindole-dihydrochloride, Sigma) in antifade solution (Vector) [50].

The hybridized metaphases were screened with a Zeiss fluorescence microscope and a minimum of twenty spreads was analyzed for each experiment. Spot-bearing metaphases were captured and analyzed with a cooled CCD camera using Cytovision software (Applied Imaging, Sunderland, UK).

\section{Alignment of the Japanese quail map with the chicken sequence}

The Ensembl Genome Browser [51] was used to perform BLASTN searches of all the markers on the quail linkage groups against the assembled chicken sequence (Table 1). Linkage and sequence maps were drawn using the MapChart program [43].

\section{Authors' contributions}

BBK and KF carried out the genotyping. BBK performed the genetic mapping work and drafted the manuscript. VF and MV carried out the FISH analyses. SL, CM and FP developed markers and produced genotypes for Type I markers. CB supervised the production of quail population 1, FM and J-LM of population 2 and MIM, MMi and SI of population 3. AV coordinated the study and finalized the manuscript.

\section{Additional material}

\section{Additional File 1}

Top BLASTN hits of Japanese quail microsatellite markers on the chicken genomic sequence. This table describes details on the BLASTN hits of the quail microsatellite markers on the chicken genome: chicken chromosome, position in $b p, \%$ similarity, lengths of the alignment, alignment score and e-value. When microsatellites were found in the chicken sequence, they were reported.

Click here for file

[http://www.biomedcentral.com/content/supplementary/14712164-7-101-S1.xls] 


\section{Additional File 2}

Top BLASTN hits of Japanese quail gene markers on the chicken genomic sequence. This table describes details on the BLASTN hits of the quail gene fragment sequences on the chicken genome: chicken chromosome, position in $b p, \%$ similarity, lengths of the alignment, alignment score and e-value.

Click here for file

[http://www.biomedcentral.com/content/supplementary/14712164-7-101-S2.xls]

\section{Acknowledgements}

The authors wish to thank Odile Roussot (INRA-LGC, Toulouse) for providing the AFLP genotypes dataset. The expert assistance of Florence Vignoles for the genotyping data acquisition and analysis is gratefully acknowledged. Thanks also to Mireille Morisson, who kindly helped in analyzing the radiation hybrid data, and to Carine Clanet for developing some of the Type I markers. Jean-Michel Faure must be thanked for the LTI and STI quail lines, which are a very valuable resource. BBK was supported by a grant from the INRA Animal Genetics Department. Sequencing and genotyping were done by using the facilities of the Toulouse Genopole MidiPyrénées platform.

\section{References}

I. Minvielle F: The future of Japanese quail for research and production. World's Poultry Science Journal 2004, 60:500-507.

2. Creuzet S, Schuler B, Couly G, Le Douarin NM: Reciprocal relationships between Fgf8 and neural crest cells in facial and forebrain development. Proc Natl Acad Sci U S A 2004, I 0 I:4843-4847.

3. Mignon-Grasteau S, Roussot O, Delaby C, Faure JM, Mills A, Leterrier C, Guemene D, Constantin P, Mills M, Lepape G, Beaumont C: Factorial correspondence analysis of fear-related behaviour traits in Japanese quail. Behav Processes 2003, 61:69-75.

4. Balthazart J, Baillien M, Charlier TD, Cornil CA, Ball GF: The neuroendocrinology of reproductive behavior in Japanese quail. Domest Anim Endocrinol 2003, 25:69-82.

5. Odeh FM, Cadd GG, Satterlee DG: Genetic characterization of stress responsiveness in Japanese quail. I. Analyses of line effects and combining abilities by diallel crosses. Poult Sci 2003, 82:25-30.

6. Lin $\mathrm{CY}$, $\mathrm{Ho} \mathrm{CH}$, Hsieh $\mathrm{YH}$, Kikuchi T: Adeno-associated virusmediated transfer of human acid maltase gene results in a transient reduction of glycogen accumulation in muscle of Japanese quail with acid maltase deficiency. Gene Ther 2002, 9:554-563.

7. van Tuinen M, Dyke GJ: Calibration of galliform molecular clocks using multiple fossils and genetic partitions. Mol Phylogenet Evol 2004, 30:74-86.

8. van Tuinen M, Hedges SB: Calibration of avian molecular clocks. Mol Biol Evol 200I, 18:206-2I3.

9. Shibusawa M, Minai S, Nishida-Umehara C, Suzuki T, Mano T, Yamada K, Namikawa T, Matsuda Y: A comparative cytogenetic study of chromosome homology between chicken and Japanese quail. Cytogenet Cell Genet 200I, 95:103-109.

10. Ito $S$, Kimura $M$, Isogai I: A sex difference in recombination values between extended brown and phosphoglucose isomerase loci in Japanese quail. Japanese Journal of Zootechnical Science 1988, 59:80I-805.

II. Ito S, Kimura M, Isogai I: Linkage between panda plumage and albumin loci in Japanese quail. Japanese Journal of Zootechnical Science 1988, 59:822-824.

12. Shibata $T$, Abe $T$ : Linkage between the loci for serum albumin and vitamin $D$ binding protein (GC) in the Japanese quail. Animal Genetics 1996, 27:195-197.

13. Minvielle F, Ito S, Inoue-Murayama M, Mizutani M, Wakasugi N: Genetic analyses of plumage color mutations on the $Z$ chromosome of Japanese quail. J Hered 2000, $91: 499-501$.
14. Roussot O, Feve K, Plisson-Petit F, Pitel F, Faure JM, Beaumont C, Vignal A: AFLP linkage map of the Japanese quail Coturnix japonica. Genet Sel Evol 2003, 35:559-572.

15. Kayang BB, Vignal A, Inoue-Murayama M, Miwa M, Monvoisin JL, Ito S, Minvielle F: A first-generation microsatellite linkage map of the Japanese quail. Anim Genet 2004, 35: 195-200.

16. Beaumont C, Roussot O, Feve K, Vignoles F, Leroux S, Pitel F, Faure JM, Mills AD, Guemene D, Sellier N, Mignon-Grasteau S, Le Roy P, Vignal A: A genome scan with AFLP markers to detect fearfulness-related QTLs in Japanese quail. Anim Genet 2005, 36:40I-407.

17. Minvielle F, Kayang BB, Inoue-Murayama M, Miwa M, Vignal A, Gourichon D, Neau A, Monvoisin JL, Ito S: Microsatellite mapping of QTL affecting growth, feed consumption, egg production, tonic immobility and body temperature of Japanese quail. BMC Genomics 2005, 6:87.

18. Miwa M, Inoue-Murayama M, Kayang BB, Vignal A, Minvielle F, Monvoisin JL, Takahashi $H$, Ito $S$ : Mapping of plumage colour and blood protein loci on the microsatellite linkage map of the Japanese quail. Anim Genet 2005, 36:396-400.

19. Morisson M, Leroux S, Jiguet-Jiglaire C, Assaf S, Pitel F, Lagarrigue S, Bardes S, Feve K, Faraut T, Milan D, Vignal A: A gene-based radiation hybrid map of chicken microchromosome 14: comparison to human and alignment to the assembled chicken sequence. Génétique Sélection Evolution 2005, 37:229-25I.

20. Morisson M, Lemiere A, Bosc S, Galan M, Plisson-Petit F, Pinton P, Delcros C, Feve K, Pitel F, Fillon V, Yerle M, Vignal A: ChickRH6: a chicken whole-genome radiation hybrid panel. Genet Sel Evol 2002, 34:521-533.

21. ChickRH Web Server [http://chickrh.toulouse.inra.fr]

22. Hillier LW, Miller W, Birney E, Warren W, Hardison RC, Ponting CP, Bork P, Burt DW, Groenen MA, Delany ME, Dodgson JB, Chinwalla AT, Cliften PF, Clifton SW, Delehaunty KD, Fronick C, Fulton RS, Graves TA, Kremitzki C, Layman D, Magrini V, McPherson JD, Miner TL, Minx P, Nash WE, Nhan MN, Nelson JO, Oddy LG, Pohl CS, Randall-Maher J, Smith SM, Wallis JW, Yang SP, Romanov MN, Rondelli CM, Paton B, Smith J, Morrice D, Daniels L, Tempest HG, Robertson L, Masabanda JS, Griffin DK, Vignal A, Fillon V, Jacobbson L, Kerje S, Andersson L, Crooijmans RP, Aerts J, van der Poel J], Ellegren $\mathrm{H}$, Caldwell RB, Hubbard SJ, Grafham DV, Kierzek AM, McLaren SR, Overton IM, Arakawa H, Beattie KJ, Bezzubov Y, Boardman PE, Bonfield JK, Croning MD, Davies RM, Francis MD, Humphray SJ, Scott CE, Taylor RG, Tickle C, Brown WR, Rogers J, Buerstedde JM, Wilson SA, Stubbs L, Ovcharenko I, Gordon L, Lucas S, Miller MM, Inoko H, Shiina T, Kaufman J, Salomonsen J, Skjoedt K, Wong GK, Wang J, Liu B, Wang J, Yu J, Yang H, Nefedov M, Koriabine M, Dejong PJ, Goodstadt L, Webber C, Dickens NJ, Letunic I, Suyama M, Torrents D, von Mering C, Zdobnov EM, Makova K, Nekrutenko A, Elnitski L, Eswara P, King DC, Yang S, Tyekucheva S, Radakrishnan A, Harris RS, Chiaromonte F, Taylor J, He J, Rijnkels M, Griffiths-Jones S, Ureta-Vidal A, Hoffman MM, Severin J, Searle SM, Law AS, Speed D, Waddington D, Cheng Z, Tuzun E, Eichler E, Bao Z, Flicek P, Shteynberg DD, Brent MR, Bye JM, Huckle EJ, Chatterji S, Dewey C, Pachter L, Kouranov A, Mourelatos Z, Hatzigeorgiou AG, Paterson AH, Ivarie R, Brandstrom $M$, Axelsson E, Backstrom N, Berlin S, Webster MT, Pourquie O, Reymond A, Ucla C, Antonarakis SE, Long M, Emerson J], Betran E, Dupanloup I, Kaessmann H, Hinrichs AS, Bejerano G, Furey TS, Harte RA, Raney B, Siepel A, Kent W], Haussler D, Eyras E, Castelo R, Abril JF, Castellano S, Camara F, Parra G, Guigo R, Bourque G, Tesler G, Pevzner PA, Smit A, Fulton LA, Mardis ER, Wilson RK: Sequence and comparative analysis of the chicken genome provide unique perspectives on vertebrate evolution. Nature 2004, 432:695-716.

23. Primmer CR, Raudsepp T, Chowdhary BP, Moller AP, Ellegren $\mathrm{H}$ : Low frequency of microsatellites in the avian genome. Genome Res 1997, 7:47I-482.

24. Pang SW, Ritland C, Carlson JE, Cheng KM: Japanese quail microsatellite loci amplified with chicken-specific primers. Anim Genet 1999, 30:195-199.

25. Inoue-Murayama M, Kayang BB, Kimura $\mathrm{K}$, Ide $\mathrm{H}$, Nomura A, Takahashi $H$, Nagamine $Y$, Takeda T, Hanada $H$, Tatsuda K, Tsudzuki M, Matsuda Y, Mizutani M, Murayama Y, Ito S: Chicken microsatellite primers are not efficient markers for Japanese quail. Anim Genet 200I, 32:7-II. 
26. Primmer $C R$, Moller AP, Ellegren $H$ : A wide-range survey of cross-species microsatellite amplification in birds. Mol Ecol 1996, 5:365-378.

27. Burt DW, Morrice DR, Sewalem A, Smith J, Paton IR, Smith EJ, Bentley J, Hocking PM: Preliminary linkage map of the turkey (Meleagris gallopavo) based on microsatellite markers. Anim Genet 2003, 34:399-409.

28. Reed KM, Chaves LD, Hall MK, Knutson TP, Harry DE: A comparative genetic map of the turkey genome. Cytogenet Genome Res 2005, I I I: I I8-127.

29. Shetty S, Griffin DK, Graves JA: Comparative painting reveals strong chromosome homology over $\mathbf{8 0}$ million years of birc evolution. Chromosome Res 1999, 7:289-295.

30. Guttenbach M, Nanda I, Feichtinger W, Masabanda JS, Griffin DK Schmid M: Comparative chromosome painting of chicken autosomal paints $\mathrm{I}-9$ in nine different bird species. Cytogenet Genome Res 2003, 103:173-184.

31. Li WH, Ellsworth DL, Krushkal J, Chang BH, Hewett-Emmett D: Rates of nucleotide substitution in primates and rodents and the generation-time effect hypothesis. Mol Phylogenet Evol 1996, 5: $182-187$

32. Koehler U, Bigoni F, Wienberg J, Stanyon R: Genomic reorganization in the concolor gibbon (Hylobates concolor) revealed by chromosome painting. Genomics 1995, 30:287-292

33. Stanyon R, Bigoni F, Slaby T, Muller S, Stone G, Bonvicino CR, Neusser M, Seuanez HN: Multi-directional chromosome painting maps homologies between species belonging to three genera of New World monkeys and humans. Chromosoma 2004 I | 3:305-3 I5.

34. Mannen H, Murata K, Kikuchi S, Fujima D, Sasazaki S, Fujiwara A, Tsuji S: Development and mapping of microsatellite markers derived from cDNA in Japanese quail (Coturnix japonica). The Journal of Poultry Science 2005, 42:263-27I.

35. Minvielle F, Coville JL, Krupa A, Monvoisin JL, Maeda Y, Okamoto S: Genetic similarity and relationships of DNA fingerprints with performance and with heterosis in Japanese quail lines from two origins and under reciprocal recurrent or withinline selection for early egg production. Genet Sel Evol 2000, 32:289-302.

36. Ito S, Tsudzuki M, Komori M, Mizutani M: Celadon: an eggshell color mutation in Japanese quail. J Hered I993, 84: I 45-I47.

37. Kayang BB, Inoue-Murayama M, Nomura A, Kimura K, Takahashi H, Mizutani M, Ito S: Fifty microsatellite markers for Japanese quail. J Hered 2000, 91:502-505.

38. Kayang BB, Inoue-Murayama M, Hoshi T, Matsuo K, Takahashi H, Minezawa M, Mizutani M, Ito S: Microsatellite loci in Japanese quail and cross-species amplification in chicken and guinea fowl. Genet Sel Evol 2002, 34:233-253.

39. Muller C, Denis M, Gentzbittel L, Faraut T: The Iccare web server: an attempt to merge sequence and mapping information for plant and animal species. Nucleic Acids Res 2004, 32:W429-34

40. Primer3 Input [http://frodo.wi.mit.edu/]

41. Budowle B, Chakraborty R, Giusti AM, Eisenberg AJ, Allan RC: Analysis of the VNTR locus DIS80 by the PCR followed by highresolution PAGE. American Journal of Human Genetics 1991, 48:137-| 44.

42. Green P, Falls K, Crooks S: Documentation for CRIMAP version 2.4. St. Louis, Washington University School of Medicine; 1990.

43. Voorrips RE: MapChart: software for the graphical presentation of linkage maps and QTLs. J Hered 2002, 93:77-78.

44. Zoorob R, Billault A, Severac V, Fillon V, Vignal A, Auffray C: Two chicken genomic libraries in the PAC and BAC cloning systems: Organization and characterization. Animal Genetics 1996, 27 (suppl. 2):69.

45. Crooijmans RP, Vrebalov J, Dijkhof RJ, van der Poel JJ, Groenen MA: Two-dimensional screening of the Wageningen chicken BAC library. Mamm Genome 2000, I I:360-363.

46. Fillon V, Morisson M, Zoorob R, Auffray C, Douaire M, Gellin J, Vignal A: Identification of 16 chicken microchromosomes by molecular markers using two-colour Fluorescent In Situ Hybridization (FISH). Chromosome Research 1998, 6:307-3 I3.

47. Morisson M, Pitel F, Fillon V, Pouzadoux A, Berge R, Vit JP, Zoorob $R$, Auffray C, Gellin J, Vignal A: Integration of chicken cytogenetic and genetic maps: 18 new polymorphic markers isolated from BAC and PAC clones. Anim Genet 1998, 29:348-355.
48. Aerts J, Crooijmans R, Cornelissen S, Hemmatian K, Veenendaal T, Jaadar A, van der Poel J, Fillon V, Vignal A, Groenen M: Integration of chicken genomic resources to enable whole-genome sequencing. Cytogenet Genome Res 2003, I 02:297-303.

49. Yerle M, Galman O, Lahbib-Mansais Y, Gellin J: Localization of the pig luteinizing hormone/choriogonadotropin receptor gene (LHCGR) by radioactive and nonradioactive in situ hybridization. Cytogenetics and Cell Genetics 1992, 59:48-5I.

50. Trask BJ, Massa H, Kenwrick S, Gitschier J: Mapping of human chromosome Xq28 by two-color fluorescence in situ hybridization of DNA sequences to interphase cell nuclei. American Journal of Human Genetics 1991, 48:1-15.

5I. Ensembl Genome Browser [http://www.ensembl.org/ index.html]

52. Ladjali-Mohammedi K, Bitgood J], Tixier-Boichard M, Ponce De Leon FA: International system for standardized avian karyotypes (ISSAK): standardized banded karyotypes of the domestic fowl (Gallus domesticus). Cytogenet Cell Genet 1999, 86:27I-276.

53. Kayang BB, Inoue-Murayama M, Takahashi H, Minezawa M, Tsudzuki $M$, Mizutani $M$, Ito $S$ : Twenty-eight new microsatellite loci in chicken and their cross-species amplification in Japanese quail and helmeted guinea fowl. Animal Science Journal 2003, 74:255-259.

54. Cheng $\mathrm{HH}$, Crittenden LB: Microsatellite markers for genetic mapping in the chicken. Poult Sci 1994, 73:539-546.

55. Cheng HH, Levin I, Vallejo RL, Khatib H, Dodgson JB, Crittenden LB Hillel J: Development of a genetic map of the chicken with markers of high utility. Poult Sci 1995, 74: I855-I874.

Publish with Bio Med Central and every scientist can read your work free of charge

"BioMed Central will be the most significant development for disseminating the results of biomedical research in our lifetime. "

Sir Paul Nurse, Cancer Research UK

Your research papers will be:

- available free of charge to the entire biomedical community

- peer reviewed and published immediately upon acceptance

- cited in PubMed and archived on PubMed Central

- yours - you keep the copyright
BioMedcentral 